\title{
The effectiveness of drama therapy on preparation for diagnostic and therapeutic procedures in children suffering from cancer
}

\author{
L'ubica llievová1* , Peter Žitný2, Zuzana Karabová3 \\ 'Department of Nursing, Faculty of Health Care and Social Work, ${ }^{2}$ Department of Psychology, Faculty of Arts, Trnava University of \\ Trnava, Trnava, Slovakia, 'Department of Pediatric Hematology and Oncology, Children's University Hospital, Bratislava, Slovakia
}

\begin{abstract}
Introduction: The integral part of the treatment of pediatric oncological patients is a range of diagnostic and therapeutic procedures. These procedures are often associated with the fear and anxiety of the suffering child. We investigated whether a psychological preparation through drama therapy and the therapeutic puppet may reduce the anxiety related to diagnostic and therapeutic procedures in the preschool or early school children suffering from cancer.
\end{abstract}

Methods: Twenty consecutive pediatric patients of preschool and early school age, with the diagnosis of lymphoblastic leukemia, were included in the study. The patients were alternatingly assigned to experimental or control group, and subjected or not subjected to drama therapy, respectively. We measured the changes in heart rate, blood pressure and respiratory rate as indicators of anxiety and fear, before and after the diagnostic or therapeutic procedures.

Results: Heart rate, blood pressure, and respiratory rate in pediatric oncological patients before and after the diagnostic or therapeutic procedure were significantly lower in the experimental group of patients.

Conclusion: Our results show that psychological preparation using drama therapy and therapeutic puppet reduced the fear and anxiety related to diagnostic or therapeutic procedures in pediatric oncological patients.

Keywords: drama therapy; therapeutic puppet; children; oncology; psychology

\section{INTRODUCTION}

According to Horňáková, drama therapy represents a complex of approaches and methods in which

\footnotetext{
*Corresponding Author: Lubica llievová. Department of Nursing, Faculty of Health Care and Social Work, Trnava University of Trnava, Univerzitné námestie 1, Trnava 91843, Slovakia. Phone: +421905 661 024, E-mail: lubica.ilievova@truni.sk
}

Submitted: 28 June 2015 / Accepted: 10 October 2015

DOI: http://dx.doi.org/10.17532/jhsci.2015.252

UNIVERSITY OF SARAJEVO FACULTY OF HEALTH STUDIES initial dramatic means are used for personal growth, emotional recovery, correction of undesirable attitudes and behavior. Improvisation is considered to be an essential mean of drama therapy. Dramatic play, verbal game, role play, script, myths, work with text, storytelling, playing with puppets, movement, playing with drawing are other means of drama therapy (1).

Oncological disease in children is life threatening and associated with recurrent diagnostic and therapeutic 
procedures (2). Cordova and Andrykowski report that during the diagnostic and therapeutic procedures in case of cancer, a child is exposed to many traumatic experiences (3). Schepper et al. describe that during a therapy small children are at increased risk of traumatic experiences from diagnostic and therapeutic procedures. According to Tanaka et al. the psychological preparation is aimed to provide children with the important information about the disease, helping them to cope with medical procedures, reduce the anxiety, increase self-esteem and reinforce the confidence in a health care team (4). In addition to the options of psychological preparation for diagnostic and therapeutic procedures, a game is a natural way of mitigating traumatic experiences in pediatric patients. Children do not always have the ability to use words to express their feelings; hence games and toys may help them to express the emotions. Games allow children to understand the situations that they experience during hospitalization, especially to express negative emotions. Through the games, children may better understand the necessity of diagnostic and therapeutic procedures (5). Game is a primary way of communication for small children and provides an effective method to understand ongoing situations in which pediatric patients are. Game provides a mean to express feelings, releases energy and provides relaxation. According to Maia et al. communication is reinforced through a game therapy and a relationship is built between a nurse and a pediatric patient (6). As reported by Ahmed et al. during a game, children reduce anxiety and more easily cope with medical procedures (7). Research has shown that short-and long-term effects can result from stressful or invasive medical procedures performed on children. Short-term effects for the pediatric patients include fear, pain, anxiety, crying, and lack of cooperation. The patients may also experience elevated anxiety and increased heart rate and blood pressure. Potential long-term effects include post-traumatic stress syndrome, fear, changes in perception and effectiveness of coping with pain, resulting in avoidance of medical care (8). The research has shown that the child's heart rate increases with his/her entry to the surgery as well as the blood pressure values and intestinal peristalsis. Breathing movements that are relevant for a growing sense of fear in a child may be disrupted (9).
During a therapeutic game, different props associated with hospital are used, such as syringes, masks, dolls with intravenous catheter etc. (10).

The aim of our study was to investigate whether a psychological preparation through drama therapy and the therapeutic puppet may reduce the anxiety and fear related to diagnostic and therapeutic procedures (intravenous cannula insertion, Port and Cath insertion, application of a subcutaneous injection and a lumbar puncture) in the preschool or early school children suffering from cancer.

\section{METHODS}

We conducted a quantitative research with a quasi-experimental design. The effects of psychological preparation of patients for diagnostic and therapeutic procedures through a game with a therapeutic puppet was verified by measuring physiological functions: blood pressure, heart and respiratory rate.

\section{Patients}

Twenty consecutive pediatric oncological patients with the diagnosis of lymphoblastic leukemia in the period from January 2012 to March 2013 were included. The inclusion criteria were the diagnosis of oncological disease requiring hospitalization, preschool or early school age and patient and parents agreement to participate in the study. Parents were asked to sign an informed consent. The first patient was allocated to experimental group, then subsequent patients have been alternately allocated to control and experimental group. The experimental group consisted of 10 patients: 8 preschool and 2 early school age children of which 3 girls and 7 boys. The control group consisted of 10 patients: 7 preschool and 3 early school age children of which 5 girls and 5 boys.

\section{Procedures}

Data were collected at the Department of Pediatric Hematology and Oncology at Children's University Hospital in Bratislava, Slovakia. The patients in control group were only informed about the diagnostic and therapeutic procedures prior were they subjected to them by medical professionals, i.e. doctors and nurses. The patients in experimental group 
underwent psychological preparation for diagnostic and therapeutic procedures through drama therapy or therapeutic puppet.

Mental preparation of experimental group patients through drama therapy and a therapeutic puppet was performed by a nurse, in both group and individual form. A group game with a therapeutic puppet took place in the playroom and rooms for infants of the Department of Pediatric Hematology and Oncology, Children's University Hospital in Bratislava, Slovakia. We realized total of 40 games with the therapeutic puppet via group game. Individual games were performed exclusively in a pediatric oncological patient room in order to eliminate interference, as well as because of leucopenia and necessity to maintain principles of barrier nursing. The number of games with the therapeutic puppet performed individually with the pediatric oncological patients was from 10 to 22 . During the game with the puppet the patients acquired specific and detailed information on diagnostic and therapeutic procedures and they became acquainted with medical devices that are used in the implementation of the procedures. Moreover, all four diagnostic and therapeutic procedures: intravenous cannula insertion, Port and Cath insertion, application of a subcutaneous injection and a lumbar puncture were simulated. The therapeutic puppet had some variability of diagnostic and therapeutic procedures.

The values of parameters defining the demonstration of fear, i.e. altered heart rate, changes in blood pressure and changes in frequency of breaths were measured and recorded in both experimental and control group at rest (during a normal daily routine) and before and after a diagnostic or therapeutic procedure. Also, the measurements were done after individual games with the therapeutic puppet. Three measurements were performed for each patient. All the measurements were conducted between 8 am to $2 \mathrm{pm}$. The measurements in both groups were each time performed by a different trained person (nurse) at the department. During the game with the therapeutic puppet patients expressed positive emotions and smiled. At the end of the game they spoke about their feelings which they had experienced when playing with the therapeutic puppet to their parents, other patients as well as nurses and psychologists.

\section{Statistical analysis}

The data were processed using descriptive statistics: absolute $(\mathrm{N})$ and relative (percentage) values, the arithmetic mean $(\mathrm{M})$, median $(\tilde{X})$, mode $(\mathrm{x})$, standard deviation (SD), maximum, and minimum. Statistical testing of differences between variables and groups were evaluated using Mann-Whitney U-test. The $\mathrm{p}$ value less than 0.05 was considered statistically significant.

\section{RESULTS}

There were 20 pediatric oncological patients of which 8 girls and 12 boys. The average age of the patients was 3.7 years ( 44 months $(S D=5.2)$ ). There were significant differences in manifestations of fear (heart rate, blood pressure, and respiratory rate) between the groups. Heart rate (HR) at rest did not significantly differ between groups $(\mathrm{U}=49$; $\mathrm{p}=0.955)$. HR before the diagnostic or therapeutic procedure in the experimental group was significantly lower compared to control group ( $\mathrm{U}=13$; $\mathrm{p}=0.004, \mathrm{r}=-0.63)$. This was also observed after the diagnostic or therapeutic procedure $(U=13.5$; $\mathrm{p}=0.004, \mathrm{r}=-0.62$ ) (Table 1 ).

Systolic blood pressure at rest did not significantly differ between the groups $(U=44 ; p=0.672$, $\mathrm{r}=-0.10)$. Systolic blood pressure before the diagnostic or therapeutic procedure was significantly lower in experimental compared to control group $(\mathrm{U}=14.5 ; \mathrm{p}=0.005, \mathrm{r}=-0.60)$. However, after the diagnostic or therapeutic procedure the values $\mathrm{did}$ not differ significantly $(\mathrm{U}=28 ; \mathrm{p}=0.101, \mathrm{r}=-0.37)$. Diastolic blood pressure was not significantly different between the groups $(U=36 ; p=0.302, r=-0.24)$. Diastolic blood pressure prior to the diagnostic or therapeutic procedure in the experimental group was significantly lower compared to control group $(\mathrm{U}=5.5 ; \mathrm{p}=0.000, \mathrm{r}=-0.75)$. The same effect was observed after the diagnostic or therapeutic procedure $(\mathrm{U}=20 ; \mathrm{p}=0.022, \mathrm{r}=-0.51)$ (Table 2).

The respiratory rate in the experimental group was not statistically significantly differ from the respiratory rate in the control group $(\mathrm{U}=49 ; \mathrm{p}=0.952)$. The difference observed between the experimental and the control group does not represent any effect $r=-0.02$. The respiratory rate before the implementation of diagnostic and therapeutic procedures 
TABLE 1. Heart rate (Mann-Whitney U)

\begin{tabular}{lcccccc}
\hline HR at rest & $\mathrm{n}$ & Median & Range & Average 0. & $\mathrm{U}$ & $\mathrm{p}$ \\
\hline Experimental group & 10 & 86 & 50 & 10.40 & 49 & 0.955 \\
Control group & 10 & 86 & 22 & 10.60 & & \\
\hline HR before a diagnostic or therapeutic procedure & 10 & 91 & & & & \\
\hline Experimental group & 10 & 118 & 58 & 13 & 0.004 \\
Control group & 10 & 88 & 42 & 6.85 & 13.5 & 0.004 \\
\hline HR after a diagnostic or therapeutic procedure & 10 & 118 & 51 & 14.15 & & \\
\hline Experimental group & 10 & &
\end{tabular}

Exact 2-way significance test

TABLE 2. Blood pressure (Mann-Whitney U)

\begin{tabular}{|c|c|c|c|c|c|c|}
\hline Blood pressure at rest & $\mathrm{n}$ & Median & Range & Average 0. & $U$ & $p$ \\
\hline Systolic - experimental & 10 & 99 & 21 & 9.90 & 44 & 0.672 \\
\hline Systolic - control & 10 & 100 & 29 & 11.10 & & \\
\hline Diastolic - experimental & 10 & 65 & 23 & 11.90 & 36 & 0.302 \\
\hline Diastolic - control & 10 & 64 & 24 & 9.10 & & \\
\hline \multicolumn{7}{|c|}{ Blood pressure before a diagnostic or therapeutic procedure } \\
\hline Systolic - experimental & 10 & 120 & 19 & 6.95 & 14.5 & 0.005 \\
\hline Systolic - control & 10 & 139 & 41 & 14.05 & & \\
\hline Diastolic - experimental & 10 & 71 & 14 & 6.05 & 5.5 & 0.000 \\
\hline Diastolic - control & 10 & 96 & 28 & 14.95 & & \\
\hline \multicolumn{7}{|c|}{ Blood pressure after a diagnostic or therapeutic procedure } \\
\hline Systolic - experimental & 10 & 116 & 19 & 8.30 & 28 & 0.101 \\
\hline Systolic - control & 10 & 130 & 30 & 12.70 & & \\
\hline Diastolic - experimental & 10 & 67 & 31 & 7.50 & 20 & 0.022 \\
\hline Diastolic - control & 10 & 82 & 34 & 13.50 & & \\
\hline
\end{tabular}

Exact 2-way significance test

in the experimental group was statistically significantly lower than the respiratory rate in the control group $(\mathrm{U}=3.5 ; \mathrm{p}=0.000)$. The difference observed between the experimental and the control group represents a large effect $r=-0.79$. The respiratory rate after the implementation of diagnostic and therapeutic procedures in the experimental group was also statistically significantly lower than the respiratory rate in the control group $(\mathrm{U}=13$; $\mathrm{p}=$ 0.003). The difference observed between the experimental and the control group represents a large effect $r=-0.63$ (Table 3).

\section{DISCUSSION}

Pulse rate, blood pressure, respiratory rate in pediatric oncological patients before and after the implementation of diagnostic and therapeutic procedures were lower in the experimental group. Patients in the experimental group were also more cooperative compared to the control group. We also observed that an important motivating factor for children in the experimental group was compliment about their good behavior and successful cooperation during the diagnostic or therapeutic procedure. This suggests that inclusion of psychological preparation through a game with a puppet to the therapeutic nursing care for pediatric oncological patients is justified.

Our research results are consistent with a study of $\mathrm{Li}$ and Lopez, which found that a therapeutic game is effective as a preparation of pediatric patients for surgery (11). In a research conducted at Children Medical Centre in Tehran, Mahmoudi-Gharaei et al. found that children age 5-12 years, who spent 
TABLE 3. Respiratory rate (Mann-Whitney U)

\begin{tabular}{|c|c|c|c|c|c|c|}
\hline Respiratory rate at rest & $\mathrm{n}$ & Median & Range & Average 0. & $\mathrm{U}$ & Sig. \\
\hline Experimental group & 10 & 23 & 8 & 10.40 & 49 & 0.952 \\
\hline Control group & 10 & 24 & 2 & 10.60 & & \\
\hline \multicolumn{7}{|c|}{ Respiratory rate before a diagnostic or therapeutic procedure } \\
\hline Experimental group & 10 & 24 & 4 & 5.85 & 3.5 & 0.000 \\
\hline Control group & 10 & 29 & 6 & 15.15 & & \\
\hline \multicolumn{7}{|c|}{ Respiratory after a diagnostic or therapeutic procedure } \\
\hline Experimental group & 10 & 22 & 10 & 6.80 & 13 & 0.003 \\
\hline Control group & 10 & 28 & 9 & 14.20 & & \\
\hline
\end{tabular}

Exact 2-way significance test

30 minutes in a playroom playing games before a scheduled surgical operation, reduced their anxiety symptoms related to surgery (12). Children suffering from cancer in the experimental group who went through the mental preparation by drama therapy using the therapeutic puppet showed personal interest and preferred individual games with the therapeutic puppet over the group games. During the game with the therapeutic puppet the patients asked for information about the diagnostic or therapeutic procedures, and were interested in medical devices as well as whether the particular procedure causes pain. The patients usually did not require the presence of their parents when playing with the therapeutic puppet. During the game they communicated with the therapeutic puppet, often using phrases learned from doctors or nurses. They also communicated with a nurse who guided the therapeutic game expressing their own feelings during the actual performance of diagnostic or therapeutic procedures. After the game with the therapeutic puppet positive emotions such as happiness, joy, satisfaction, and pleasure remained.

The results our study suggest a necessity for emphasizing the challenges for further examination of the issue of pediatric patients' mental preparation for diagnostic and therapeutic procedures. We consider the fact that we can help patients cope with stressful events, so we might increase quality of life meanwhile medical therapy. Playing with the therapeutic puppet provided a pediatric oncological patient with information prior to plan diagnostic and therapeutic procedures: exemplification and specific information on medical devices, description and chronology of the course of diagnostic and therapeutic procedures; and also reduced symptoms of distress during the implementation of diagnostic and therapeutic procedures. By means of a game with the therapeutic puppet, children suffering from cancer eliminated symptoms of social isolation and became active during the treatment process, as well as they ceased to be only objects of healthcare workers. Thanks to this game with the therapeutic puppet we can conclude that health professionals have earned trust of children who cooperated as well as communicated more effectively. Drama therapy also helps to make a life of a pediatric patient as close as possible to a normal child's life. If pediatric clinics want to provide comprehensive nursing care of pediatric patients, it would be appropriate if drama therapy became a part of a treatment plan for each pediatric patient. We recommend including other operations into the preparation of a pediatric patient for diagnostic and therapeutic procedures using drama therapy in order to avoid stereotypes in behavior of a child as well as nurses. Application of drama therapy in nursing contributes also to the fulfillment of individual points of the Charter of Rights of Hospitalized Child. It is important to include elements of drama therapy into nursing care to see a nurse as a person who does not cause pain, but rather as a person who helps pediatric patients and whom they can trust. If a pediatric patient with regard to their health situation experience anxiety, uncertainty and fear, then they require the atmosphere of safety, understanding and support. If a child is not able to experience security and trust it may increase anxiety and the healing process can be complicated and it can lengthen.

Our observations involve a specific group of pediatric patients, certain situations, and only some of 
the possible conceptualizations of variables. We are aware of fact that our sample consists of relatively small number of research participants and therefore, we may not know whether this findings may be generalized to other clinical groups of pediatric oncological patients.

\section{CONCLUSION}

Our results show that psychological preparation using drama therapy and therapeutic puppet reduced the fear and anxiety related to diagnostic or therapeutic procedures in pediatric oncological patients.

\section{CONFLICT OF INTERESTS}

The authors declare no conflict of interest.

\section{ACKNOWLEDGEMENTS}

Thanks to Elizabeth Szeteiova, a student of the Academy of Fine Arts in Bratislava, Slovakia, for producing a therapeutic puppet.

\section{REFERENCES}

1. Horňáko-vá M. Liečebná pedagogika pre pomáhajúce profesie.Bratislava: Občianske združenie Sociálna práca. 2007;176(3):12.
2. Schepper F, Schachtschabel S, Christiansen H. 'Do not worry, it hurts!' psychological preparation for medical procedures in pediatric oncology. Klinische Pädiatrie. 2012;224(3): 201-206.

3. Cordova MJ, Andrykowski MA. Responses to cancer diagnosis and treatment: posttraumatic stress and posttraumatic growth. Seminars Clinical Neuropsychiatry. 2003;8(4):286-296.

4. Tanaka K. Yoshikawa N, Kudo N, Negishi Y, Shimizu T, Hayata N. A need for play specialists in Japanese children's wards. Paediatric Nursing. 2010;22(6):31-32.

http://dx.doi.org/10.7748/paed2010.07.22.6.31.c7842.

5. Clark A. Helping Children Understand and Cope with the Experience of Hospitalization. Springer. 2002;1(1):1-10.

6. Maia EB, Ribeiro CA, De Borba RI. Understanding nurses' awareness as to the use of therapeutic play in child care. Rev Esc Enferm USP. 2011;45(4):839-846.

http://dx.doi.org/10.1590/S0080-62342011000400007.

7. Ahmed Ml, Farrell M.A, Parrish K, Karla A. Preoperative anxiety in children risk factors and non-pharmacological management. Middle East Journal of Anesthesiology. 2011;21(2):153-164.

8. Alexander, M. Managing patient stress in pediatric radiology. Radiology technologic. 2012; 83, (6):549-560.

9. Valenta M. Herní specialista somatopedii. 2008; 3. vyd. Olomouc: Univerzita Palackého v Olomouci, $218 \mathrm{~s}$.

10. La Motte J. Psychotherapeutic Techniques and Play Therapy with Children Who Experienced Trauma: A Review of The Literature. The Undergraduate Review. 2011;7(15):68-72.

11. Li, H. C. W. and Lopez, V. (2008), Effectiveness and Appropriateness of Therapeutic Play Intervention in Preparing Children for Surgery: A Randomized Controlled Trial Study. Journal for Specialists in Pediatric Nursing, 13: 63-73.

http://dx.doi.org/10.1111/j.1744-6155.2008.00138.x.

12. Mahmoudi-Gharaei J., Moharari F., Shahrivar Z., Ashjaei B., Ali Rezaei N., Parizad Zh. Effect of Preoperative Play Interventions on Post Surgery Anxiety. Journal Psychiatry. 2008;3,(4):20-24. 